\title{
Tecnologia e humanização em ambientes intensivos
}

\author{
Technology and humanization in critical care environments \\ Tecnología y humanización en ambientes intensivos
}

\section{Isaac Rosa Maroues', Agnaldo Rodrigues de Souza'}

'Universidade de Santo Amaro. Curso de Enfermagem. São Paulo, SP

Submissão: $17 / 05 / 2008$

Aprovação: 12/12/2009

\section{RESUMO}

Devido aos avanços obtidos com a revolução industrial através de descobertas em maquinário tecnológico, a relação profissionalpaciente tem se tornado cada vez mais automatizada, deixando a humanização em segundo plano. O objetivo deste trabalho foi realizar uma reflexão o processo de humanização em ambientes intensivos e sua relação com a inserção da tecnologia. A tecnologia contribui de maneira efetiva no tratamento de pacientes Que exigem cuidados extremos. Entretanto, se estiver associada a humanização pode alcançar resultados satisfatórios, melhorando assim o acolhimento do cliente Que recebe cuidados providenciados pela tecnologia.

Descritores: Tecnologia; Humanização; Enfermagem; Relações profissional-paciente.

\section{ABSTRACT}

Because of the advances made with the industrial revolution through technological discoveries in machinery, professional-patient relationship has become increasingly automated, leaving the humanization in the background. The purpose of this paper was to reflect about the humanization process in intensive environments and its relation with the technology insertion. Technology contributes as an effective way to treat patients who require extreme care. However, if it is associated with humanization can achieves satisfactory results, improving the host of customer who receives the care provided by technology.

Key words: Technology; Humanization; Nursing; Professional-patient relations.

\section{RESUMEN}

Debido a los avances logrados con la revolución industrial a través de descubrimientos tecnológicos en maQuinaria, la relación profesionalpaciente se ha convertido cada vez más automatizada, lo que deja la humanización en el fondo. El objetivo de este trabajo fue reflexionar acerca del proceso de humanización y su relación con la inserción de la tecnología. La tecnología contribuye de manera eficaz en el tratamiento de pacientes que requieren atención extrema. Sin embargo, si se asocia con la humanización puede lograr resultados satisfactorios, mejorando así la acogida al cliente que recibe la atención promovida por la tecnología.

Descriptores: Tecnología; Humanización; Enfermería; Relaciones profesional-paciente. 


\section{INTRODUÇÃO}

Refletir acerca do cuidado na perspectiva da tecnologia nos leva a repensar a inerente capacidade do ser humano em buscar inovações capazes de transformar seu cotidiano, visando uma melhor Qualidade de vida e satisfação pessoal. Para podermos entender o contexto atual Que reflete a arte do cuidado inserida em um mundo tecnológico, é necessário compreender o desenvolvimento histórico e cultural da sociedade.

A primeira revolução técnico-científica pode ser situada entre o final do século XVIII e o início do século XIX, cujas transformações tiveram mérito de substituir na produção, a força física do homem pela energia das máouinas, primeiramente pelo vapor e após, pela eletricidade. A tecnologia passa a ser compreendida como o estudo ou a atividade da utilização de teorias, métodos e processos científicos, para solução de problemas técnicos ${ }^{(1)}$.

No campo da saúde a introdução de instrumentos para o ato cirúrgico e o surgimento de equipamentos diagnósticos foram os movimentos mais evidentes da inserção da tecnologia na terapêutica. A Revolução Industrial e a Segunda Guerra Mundial proporcionaram a união da ciência à tecnologia, adequando-a aos princípios científicos, passando a utilização dos equipamentos mais simples aos sofisticados ${ }^{(1)}$.

No Brasil, por volta dos anos 1990, a investigação sistematizada em busca de um corpo de conhecimentos específicos de enfermagem e também a construção de modelos conceituais para a sua prática começaram a tomar destaque. A construção do conhecimento da enfermagem teve suas primeiras tentativas Quando surgiu a sistematização das técnicas e, mais tarde, com a preocupação em organizar princípios científicos para nortear a sua prática. Com o advento da fundamentação científica do cuidado de enfermagem houve o reconhecimento da expressão tecnológica do cuidado, tanto como processo e como produto. Assim, percebemos Que na história da civilização a tecnologia e o cuidado estão fortemente relacionados ${ }^{(2)}$.

\section{INTEGRAÇÃO DA TECNOLOGIA E HUMANIZAÇÃO}

A enfermagem tem o compromisso de contribuir para o aprimoramento das condições de viver e ser saudável, buscando uma melhor Qualidade de vida para todos os seres. Pode contribuir de maneira mais efetiva através do desenvolvimento de uma consciência de cuidado presente na prática, no ensino, na teorização e na pesquisa ${ }^{(3)}$.

O desenvolvimento do conhecimento de enfermagem pode ser feito através de uma reflexão das ações realizadas durante as atividades diárias e principalmente pela vontade de avançar, somando ao fazer tecnicista um fazer/pensar mais humanitário. Entretanto, durante este processo, faz-se necessário a realização de estudos Que explorem e cultivem esse fenômeno em nossa sociedade, contribuindo para uma melhor Qualidade dele ${ }^{(3)}$.

Ao adQuirir a formação, os profissionais Que têm prioriorizado a especialização, sendo cada vez mais capacitados e habilitados a oferecer o melhor tratamento e conseQuentemente recuperação ou cura do doente. Mediante a tal esforço alguns aspectos inerentes ao ser humano têm sido deixado em segundo plano, tais como: seus valores, crenças, sentimentos e emoções ${ }^{(2)}$.
Visando uma mudança neste panorama, o Ministério da Saúde criou, em 2001, o Programa Nacional de Humanização da Assistência Hospitalar (PNHAH), com simples objetivo de humanizar a assistência prestada aos pacientes atendidos em hospitais públicos. Em 2003, torna-se uma Política Nacional de Humanização, ou Humaniza-SUS, abrangendo a saúde como um todo ${ }^{(4)}$.

\section{Tecnologia}

$\mathrm{O}$ atendimento de Qualidade é um é direito de cada pessoa ${ }^{(5)}$. Para tanto, durante os últimos anos tem-se desenvolvido cada vez mais técnicas e dispositivos Que facilitem e melhorem as condições de atendimento ao cliente, buscando diminuir sua internação e agilidade no tratamento.

Algumas das características peculiares de uma Unidade de Tratamento Intensivo (UTI), são: ambiente permeado de tecnologia de última geração, situações iminentes de emergência e necessidades de agilidade e habilidade no atendimento ao cliente ${ }^{(4)}$. Estas unidades são organizadas de maneira a prestar assistência especializada aos clientes em estado crítico, com risco de vida, exigindo controle e assistência médica e de enfermagem ininterruptas. Em virtude desses fatos, justifica-se a introdução de tecnologias cada vez mais aprimoradas Que buscam, por meio de aparelhos, preservar e manter a vida do paciente em estado crítico, através de terapêuticas e controles mais eficazes, o Que exige profissionais de saúde alta capacitação e habilidade(3).

Tais equipamentos favorecem o atendimento imediato, possibilitando segurança para toda a equipe da UTI. Porém, em contrapartida, podem contribuir para tornar as relações humanas mais distantes, fazendo com Que o cliente se sinta abandonado, levantando a premissa de que talvez saibamos mais sobre a máquina e pouco sobre o cliente que estamos cuidando, tratando-o às vezes como objeto das determinações ou do cuidado ${ }^{(3)}$.

Os avanços tecnológicos são reflexo da reestrutuação produtiva Que está ocorrendo, mais intensamente na produção industrial, desde o final dos anos 1970 e, no Brasil, nos anos 1990, gerando então, necessidade de trabalhadores Qualificados para manipulação dos artefatos tecnológicos tais como ventiladores, monitores cardíacos, bombas de infusão, dentre outros ${ }^{(2,6-7)}$.

Além disso, a tecnologia pode ser compreendida de forma ampliada: a tecnologia representada por máeuinas e aparelhos (tecnologia dura), a tecnologia Que engloba o saber profissional que pode ser estrutura e protocolizado (tecnologia leve-dura) e a tecnologia leve oue se refere à cumplicidade, à responsabilização e ao vínculo manifestados na relação entre usuário e trabalhador de saúde ${ }^{(8)}$.

Produzir tecnologia é buscar a produção de "coisas" Que podem ser materiais como produtos simbólicos Que satisfaçam necessidades. Salientando assim conhecimento para o desenvolvimento de tais facilidades ${ }^{(2,6)}$.

A tecnologia pode ser classificada em três tipos:

- Tecnologia dura: equipamentos do tipo máeuina, instrumental, normas rotinas e estruturas organizacionais;

- Tecnologia leve-dura: são saberes estruturados, como fisiologia, anatomia, psicologia, clínica médica, cirúrgica, dentre outro;

- Tecnologia leve: são implicadas com o conhecimento da produção das relações entre sujeitos. Presente no espaço trabalhador-usuário, e só se materializam em atos, tais como acolhimento, produção de vínculo, encontros de subjetividade e 
autonomização.

A dimensão desumanizante da ciência e tecnologia se dá, portanto, na medida em Que se fica reduzido a objetos da própria técnica e objetos despersonalizados de uma investigação Que se propõe fria e objetiva. O saber técnico supõe saber Qual é o bem de seu paciente, independentemente de sua opinião(9).

\section{Humanização}

A humanização da assistência tornou-se um desafio, já Que a tecnologia cada vez mais se supera e, muitas vezes, verifica-se o envolvimento com as máquinas, o que facilita o esquecimento de Que está se cuidando de pessoas. Existem outras pessoas dividindo conosco esse espaço, como pacientes, familiares, outros profissionais, tornando o ambiente frio e muitas vezes sem afeto ${ }^{(10)}$.

Humanizar é tornar humano, dar condição humana, agir com bondade natural, humanar. Tornar benévolo, afável, fazer adeuirir hábitos sociais polidos, civilizar ${ }^{(1)}$.

A partir deste conceito é importante abordar a humanização em UTI, pois são locais destinados à prestação de assistência especializada a pacientes em estado crítico, exigindo controle rígido de parâmetros vitais e assistência de enfermagem contínua e intensiva $^{(4)}$.

O conceito de humanização pode ser traduzido como uma busca incessante do conforto físico, psíQuico e espiritual do paciente, família e equipe, elucidando assim a importância da mesma durante o período da internação(6).

Sendo assim, a humanização representa um conjunto de iniciativas Que visam a produção de cuidados em saúde, capazes de conciliar a melhor tecnologia disponível com promoção de acolhimento, respeito ético e cultural do paciente, espaços de trabalho favoráveis ao bom exercício técnico e a satisfação dos profissionais de saúde e usuários.

A humanização do cliente pode ser percebida na Constituição Federal, Que garante a todos o acesso à assistência à saúde. A Carta dos Direitos do Paciente, a Comissão Conjunta para Acreditação de Hospitais para a América Latina e o Programa Nacional de Humanização da Assistência Hospitalar - PNHAH propostos pelo Ministério da Saúde, em 2001, são documentos Que determinam o modo e o campo de atuação das instituições e dos profissionais de saúde rumo à humanização dos seus usuários, garantindo um melhor atendimento para o cliente ${ }^{(12)}$.

\section{Tecnologia e Humanização}

O cuidado de enfermagem e a tecnologia estão interligados, uma vez Que a profissão está comprometida com princípios, leis e teorias, e a tecnologia consiste na expressão desse conhecimento científico, e em sua própria transformação.

Por entendermos o cuidado de enfermagem como um complexo construto, acreditamos Que ele possa ter diferentes dimensões, o Que não significa dizer Que isso possa inviabilizar o entendimento de Que ele é humano, ainda Que tenhamos Que nos apropriar de tecnologias e máeuinas para cuidar. A apropriação de tecnologias, em particular aquelas entendidas como duras, é considerada como fundamental para cuidar e assistir, pois elas contribuem sobremaneira na ampliação da capacidade natural de sentir, embora exija da enfermagem um alto grau de Qualificação profissional ${ }^{(13-14)}$.

Desta forma, as UTIs são consideradas locais especiais Que demandam um alto grau de especialização do trabalho da equipe de enfermagem e exigem do trabalhador um treinamento adequado, uma afinidade para atuar em unidades fechadas e uma resistência diferenciada dos demais Que atuam em outras áreas hospitalares ${ }^{(15-16)}$.

No contexto atual, o cuidado em UTI hoje, mais do que no passado, tem sido distinguido pela incorporação/utilização de novas tecnologias, abrindo novos horizontes e novas perspectivas para a melhoria da Qualidade do trabalho/assistência e de vida dos sujeitos Que cuidam e daqueles Que são cuidados.

\section{CONSIDERAÇÕES FINAIS}

Conclui-se Que as reflexões acerca do cuidado de enfermagem em terapia intensiva deverão passar por uma revisão mais aprofundada acerca dos conceitos de cuidado e da utilização de tecnologias nesta unidade.

Crê-se oportuno Que consideremos também os sentidos atribuídos à terapia intensiva, não só por parte dos profissionais de enfermagem, mas também por parte do usuário do mesmo.

Dar a devida atenção às má uuinas não é necessariamente uma ação mecanicista. Entretanto, cuidar de um cliente dependente da máeuina é uma ação humana, ainda Que tenhamos Que pensar também nessa máquina e no sentido Que ela tem para nós.

A grande diversidade tecnológica utilizada pela enfermagem nessas unidades para auxiliar na manutenção da vida é uma realidade Que ao mesmo tempo encanta e assusta. Não obstante, apresenta aos profissionais Que lidam com ela constantes desafios e Questões, exigindo-lhes profundas e constantes reflexões acerca da sua aplicabilidade no cuidado.

Vale destacar Que cuidar de máeuinas não é um discurso teóricoprático tão absurdo, pois se ela em muitos casos mantém o cliente vivo, isso só é possível porQue direta ou indiretamente cuidamos delas também.

Programar as máquinas bem como ajustar seus parâmetros e alarmes e supervisionar seu funcionamento são exemplos de cuidados para com elas e com os clientes Que delas se beneficiam. No entanto, ao fazermos isso, lançamos mão de conhecimentos técnicos e racionais Que fundamentam nossas ações no trato com as máQuinas, contribuindo para Que essas ações sejam interpretadas como práticas desumanas, principalmente Quando estes cuidados provocam no corpo do cliente sinais de dor, sofrimento e desconforto.

Assim, vale destacar Que precisamos entender que os conceitos de cuidado de enfermagem e as definições que interessam para a profissão são dinâmicos e deverão variar de acordo com o contexto, com o movimento do mundo e, consequentemente, com as reconfigurações do humano. Portanto, o que se opõe ao cuidado é o descuidado, e isso de fato poderá estar ocorrendo e equivocadamente sendo denominada desumanização.

Compreende-se que a humanização dos serviços de saúde implica em transformação do próprio modo como se concebe o usuário do serviço - de objeto passivo ao sujeito, de necessitado de atos de caridade àQuele Que exerce o direito de ser usuário de um serviço Que garanta ações técnica, política e eticamente seguras, prestadas por trabalhadores responsáveis. Enfim, essa transformação refere-se a um posicionamento político Que enfoca a saúde em uma dimensão ampliada, relacionada às condições de vida inseridas em um contexto sociopolítico e econômico. 
No processo de humanização do atendimento em saúde/ enfermagem, intui-se Que, diferentemente da perspectiva caritativa Que aponta o trabalhador como possuidor de determinadas características previamente definidas e até idealizadas, é fundamental a sua participação como sujeito Que, sendo também humano, pode ser capaz de atitudes humanas e "desumanas" construídas nas relações com o outro no cotidiano.

Nesse contexto, é fundamental não perder de vista a reflexão e o senso crítico Que nos auxiliem no Questionamento de nossas ações, no sentido de desenvolver a solidariedade e o compromisso.

\section{REFERÊNCIAS}

I. Barra DCC, Nascimento ERP, Martins II, Albuquerque GL, Erdmann AL. Evolução histórica e impacto da tecnologia na área de saúde e da enfermagem. Rev Eletrônica Enferm 2006; 8(3): 422-30.

2. Martins II, Nascimento ERP. A tecnologia e a organização do trabalho da Enfermagem em UTI. Are Catarinenses Med 2005; 34(4): 23-7.

3. Nascimento KC, Erdmann AL. Cuidado transpessoal de enfermagem a seres humanos em unidade crítica. Rev Enferm UERI 2006; I4(3): 333-4I.

4. Salicio DMBS, Gaiva MAM. O significado de humanização da assistência para enfermeiros Que atuam em UTI. Rev Eletrônica Enferm 2006; 8(3): 370-6.

5. Abrão ACFV. Humanização da assistência e tecnologia [editorial]. Acta Paul Enferm 2003; 16(4): 5.

6. Bolela F, Jericó MC. Unidades de terapia intensiva: considerações da literatura acerca das dificuldades e estratégias para sua humanização. Esc Anna Nery Rev Enferm 2006; 10(2).

7. Barra DCC, Nascimento ERP, Martins II, Albuquerque GL, Erdmann AL. Impacto da tecnologia na área da saúde e da enfermagem. Rev Eletrônica Enferm 2006; 8(3): 422-30.

8. Casate JC, Corrêa AK. Humanização do atendimento em saúde: conhecimento veiculado na literatura brasileira de enfermagem. Rev Latino-am Enfermagem 2005; 13(1): 105-I1.
9. Oliveira BRG, Collet N, Vieira CS. A humanização na assistência à saúde. Rev Latino-am Enfermagem 2006; 14(2): 277-84.

10. Barbosa ECV, Rodrigues BMRD. Humanização nas relações com a família: um desafio para a enfermagem em UTI Pediátrica. Acta Scientiarum Health Sci 2004; 26(I): 205-I 2.

11. Ferreira AB. Dicionário Aurélio da Língua Portuguesa. São Paulo; 2007.

12. Matsuda LM, Silva N, Tisolin AM. Humanização da assistência de enfermagem: estudo com clientes no período pós-internação de uma UTI-Adulto. Acta Scientiarum Health Sci 2003, 25(2): 163-70.

13. Barbosa IA, Silva MJP. Cuidado humanizado de enfermagem: o agir com respeito em um hospital universitário. Rev Bras Enferm 2007; 60(5): 546-5I.

14. Backes DS, Lunardi Filho WD, Lunardi VL. O processo de humanização do ambiente hospitalar centrado no trabalhador. Rev Esc Enferm USP 2006; 40(2): 22 I-7.

15. Arone EM, Cunha ICKO. Tecnologia e Humanização: desafios gerenciados pelo enfermeiro em prol da integridade da assistência. Brasília, Rev Bras Enferm 2007; 60(6): 72 I-3.

16. Souza LNA, Padilha MICS. A humanização na UTI - um caminho em construção. Texto Contexto Enferm 2000; 9(2): 324-35. 